\title{
Odd Helge Gilja's summary of the published DUDS obituary of Hans Henrik Holm 16.9.1931-24.7.2016
}

The EFSUMB Honorary member Hans Henrik Holm (HHH) and the founder of the Danish Ultrasound Diagnostic Society (DUDS) passed away at the age of 84. HHH's importance to both Danish and international ultrasound imaging simply cannot be overstated. Even his nicknames "The father of interventional ultrasound" and "The father of Danish ultrasound" speaks for the greatness of his achievements. HHH graduated from Copenhagen University in 1958. As a resident in the department of urology at Gentofte Hospital in the beginning of the 60's his vision for ultrasound was recognized early. HHH established a laboratory of ultrasound with a dedicated group of other young residents at the hospital. No B-mode scanners were commercially available at that time, so HHH had to build one. HHH did the first ultrasound image guided puncture of a renal cyst and he named the technique '2-D static scanning puncture.' The procedure was filmed and presented at the AIUM meeting in USA in 1970 intervention. Other achievements were a transurethral ultrasound scanner in 1973 and presentation of the real-time ultrasound guided puncture technique using a linear array transducer in
1974. In February 1974, the Danish Society of Diagnostic Ultrasound was founded and $\mathrm{HHH}$ was elected as its first president.

In 1983, Holm introduced the transrectal ultrasound (TRUS) guided implantation technique for the treatment of prostatic cancer (brachytherapy). Several procedures, equipment and applications of interventional ultrasound were born there in collaboration with industrial partners. Ultrasound guided ablation techniques, using laser, microwaves, radiofrequency, cryo and radioactive seeds were developed or clinically implemented because $\mathrm{HHH}$ had created an unsurpassed environment for research and innovation. There was a constant flow of doctors visiting the Ultrasound Department from all over the world. All returned to their homelands stimulated and enriched by $\mathrm{HHH}$, and several of them returned and founded ultrasound units in their hospitals after the concept they had experienced.

HHH had an incredible drive and commitment and combined with his winning character he was in charge of many international congresses. The culmination was

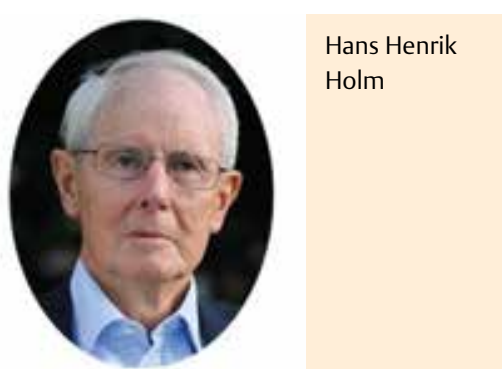

without a doubt the ultrasound World Congress WFUMB 1991 when Hans Henrik was president. HHH became honorary member of several international scientific societies and received numerous awards for his work including The Novo Award and The August Krogh Prize. He was also Honorary Member of the Norwegian Society for Diagnostic Ultrasound (NFUD). He also received the great honour to be appointed adjunct professor at Copenhagen University and honorary professor at the world's oldest university, the University of Bologna. After his retirement $\mathrm{HHH}$ continued his genuine interest in the development of Danish ultrasound and for many years, he was a welcome participant at the annual scientific meeting in DUDS. Our thoughts are with his wife Kirsten and their three children Jacob, Niels and Trine with families. We know they will miss him dearly, so do we.

Bjørn Skjoldbye, Christian Nolsøe, and Odd Helge Gilja 